\title{
An intensive smoking cessation intervention reduced hospital admissions and mortality in high risk smokers with CVD
}

Mohiuddin SM, Mooss AN, Hunter CB, et al. Intensive smoking cessation intervention reduces mortality in high-risk smokers with cardiovascular disease. Chest 2007;131:446-52.

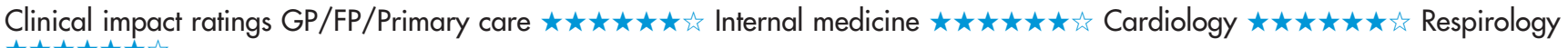

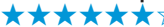

In high risk smokers hospitalized for cardiovascular disease, does an intensive behavioural plus pharmacotherapy smoking cessation intervention plus usual care after discharge reduce hospital admissions and mortality more than usual care alone?

\section{METHODS}

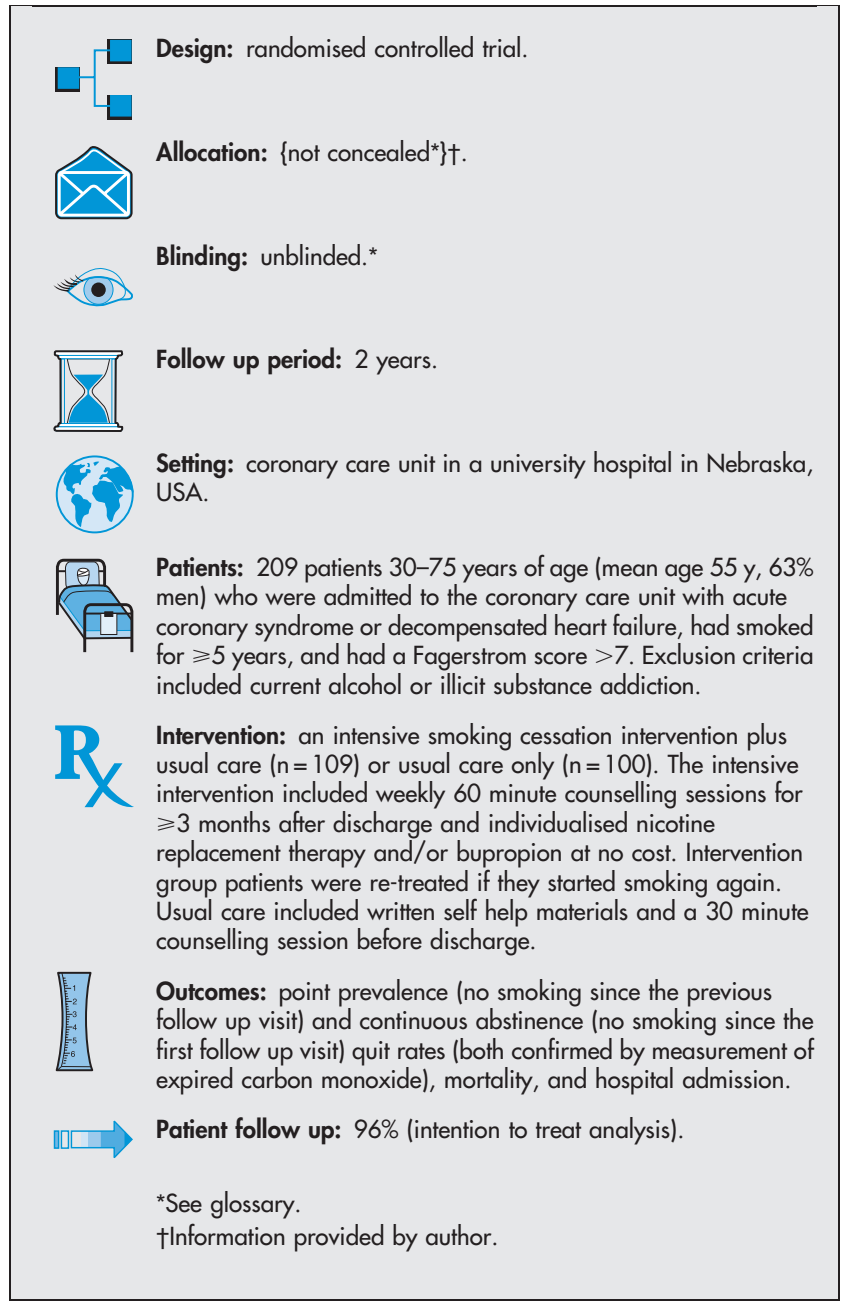

\section{MAIN RESULTS}

The intensive intervention group had higher quit rates than the usual care group throughout the follow up period and at 2 years (table). The intensive intervention led to fewer hospital admissions and lower all cause mortality (table).

\section{CONCLUSION}

In high risk smokers hospitalised with cardiovascular disease, an intensive smoking cessation intervention reduced hospital admissions and all cause mortality more than usual care only.

For correspondence: Dr D E Hilleman, Creighton University Cardiac Center, Omaha, NE, USA. hilleman@creighton.edu

Source of funding: State of Nebraska Cancer and Smoking Disease Research fund.
Abstract and commentary also appear in ACP Journal Club.

Intensive smoking cessation intervention plus usual care $v$ usual care only in high risk smokers hospitalised for CVD*

\begin{tabular}{|c|c|c|c|c|}
\hline Outcomes at $2 y$ & Intervention & Control & RBI $(95 \% \mathrm{Cl})$ & NNT (Cl) \\
\hline \multirow{3}{*}{$\begin{array}{l}\text { Point prevalence } \\
\text { quit rate } \\
\text { Continuous } \\
\text { abstinence quit } \\
\text { rate }\end{array}$} & $39 \%$ & $9 \%$ & $\begin{array}{l}338 \% \\
(132 \text { to } 752)\end{array}$ & $4(3$ to 6$)$ \\
\hline & $33 \%$ & $9 \%$ & $267 \%$ & 5 (3 to 8$)$ \\
\hline & & & RRR (CI) & \\
\hline All cause death & $2.8 \%$ & $12 \%$ & $77 \%$ (27 to 93 ) & 11 (6 to 41$)$ \\
\hline CVD death & $2.8 \%$ & $9 \%$ & & $\begin{array}{l}\text { Not } \\
\text { significant }\end{array}$ \\
\hline $\begin{array}{l}\text { All cause hospital } \\
\text { admissions }\end{array}$ & $23 \%$ & $41 \%$ & $44 \%$ (16 to 63 ) & $6(4$ to 19$)$ \\
\hline $\begin{array}{l}\text { CVD hospital } \\
\text { admissions }\end{array}$ & $18 \%$ & $37 \%$ & $50 \%$ (21 to 69$)$ & $6(4$ to 16$)$ \\
\hline
\end{tabular}

${ }^{*} \mathrm{CVD}=$ cardiovascular disease. Other abbreviations defined in glossary; RBI, RRR, NNT, and Cl calculated from data in article.

\section{Commentory}

7 he small but well designed clinical trial by Mohiuddin et al found that a smoking cessation programme increased quit rates and reduced hospital admissions and mortality in high risk cardiac patients. Several aspects of their cessation intervention deserve comment. First, although the Joint Commission on Accreditation of Healthcare Organizations quality initiatives encourage US hospitals to identify and intervene in smokers admitted with acute cardiac syndromes, few provide the 30 minute inpatient counselling session described here. Second, the intervention included weekly counselling for 3 months after discharge. Outpatient counselling is unavailable or not covered for most Americans. In 2005, only 14 states covered cessation counselling for all Medicaid recipients and only 1 state (Oregon) covered all forms of counselling and medication. ${ }^{1}$ Third, medications, which probably doubled quit rates, ${ }^{2}$ were provided to patients free of charge, and $75 \%$ of patients in the intervention group took advantage of them. Fourth, multiple opportunities for re-treatment were allowed. We know that tobacco dependence is a chronic, relapsing condition, and $>25 \%$ of the intervention group were re-treated during the study period.

This landmark study calls to mind the first study of lipid lowering that showed a significant reduction in mortality and forever changed clinical practice. ${ }^{3}$ Even if we ignore the effecton mortality, the costs to identify and intervene in smokers are minimal compared with hospital costs. The study should serve as a call to all payers, public and private, to re-evaluate their coverage for intensive tobacco cessation interventions. Physicians need to advocate for increasing coverage and decreasing barriers to effective smoking cessation treatments. Charles J Bentz, MD, FACP Providence, St Vincent Hospital and Medical Center, Portland, Oregon,

1 Centers for Disease Control and Prevention (CDC). MMWR Morb Mortal Wkly Rep 2006;55:1194-7.

2 Hughes JR. CA Cancer J Clin 2000;50:143-51.

3 Pedersen T, Kjekshus J, Berg K, et al. Lancet 1994;344:1383-9. 